\title{
A INFORMALIDADE LABORATIVA SOB O ENFOQUE INTERDISCIPLINAR: DIFERENTES PERSPECTIVAS PARA UM FENÔMENO COMPLEXO EM
}

TEMPOS DE PANDEMIA | LABOR INFORMALITY UNDER THE INTERDISCIPLINARY APPROACH: DIFFERENT PERSPECTIVES FOR A COMPLEX PHENOMENON IN PANDEMIC TIMES

LENÍCIO LEMOS PIMENTEL ALEXANDRE PIMENTA BATISTA PEREIRA

RESUMO I O artigo explora as abordagens conceituais da informalidade laborativa, considerando-se a relevância do debate em face da pandemia do novo coronavírus. Tem por objetivo apresentar uma definição interdisciplinar ao fenômeno, aproveitando-se dos instrumentais teóricos do Direito, da Economia e da Sociologia. Propõe-se, ainda, análise do conceito integrado da informalidade laborativa em cotejo com a Lei $n^{\circ} 13.982$, de 02 de abril de 2020, que criou o auxílio emergencial. A metodologia centrase na revisão bibliográfica em cada campo de conhecimento. A informalidade laborativa traduz-se no conjunto de atividades econômicas e profissionais não abarcadas pelo ordenamento jurídico, e desenvolvidas em contexto alternativo e residual ao mercado de trabalho formal, cujas ações dos sujeitos são toleradas pelo Estado, e orientadas, essencialmente, à garantia de sobrevivência. Constata-se, por fim, que $\mathrm{o}$ estudo interdisciplinar da informalidade laborativa oferece os substratos teóricos necessários à compreensão das reais demandas daquele grupo vulnerável em momentos de profunda desestabilização socioeconômica.

\section{PALAVRAS-CHAVE}

Informalidade. Direito. Economia. Sociologia. Coronavírus.
ABSTRACT | This study explores conceptual approaches to work informality from different perspectives, as a debate during the COVID-19 pandemic. It aims to propose an interdisciplinary definition of the phenomenon, taking advantage of the theoretical instruments of Law, Economics, and Sociology. An analysis of the integrated concept of labor informality is proposed in comparison with Brazilian Law No. 13,982, of April 2, 2020, which created an emergency aid due to the pandemic. A bibliographic review in each field of knowledge was conducted. Labor informality consists of the set of economic and professional activities not covered by the legal system and developed in an alternative and residual context to the formal labor market, whose subjects' actions, in general, are tolerated by the State, and guided, essentially, towards ensuring survival. Finally, the interdisciplinary study of informal work offers theoretical bases to understand the demands of vulnerable groups in times of profound socio-economic destabilization.

KEYWORDS | Informality. Law. Economics. Sociology. Coronavirus. 


\section{INTRODUÇÃO}

s profundas transformações ocorridas no mundo do trabalho
nas últimas décadas, com a superação do regime fordista de
produção e o consequente declínio das políticas de bem-estar social, impactaram as bases fundantes da relação laboral assalariada.

Segundo Antunes (2015), a verticalização do locus de produção característica do fordismo -, que se traduz na concentração das atividades da fábrica em um único espaço, propiciava a aglutinação dos trabalhadores; situação que levava ao fortalecimento das práticas associativistas, instrumento essencial para fazer frente ao capital, no contexto de evolução dos direitos sociais.

Em substituição ao referido modelo, na esteira das políticas neoliberais capitaneadas, a partir da década de 1970, pelos países de economia avançada, surge o sistema de produção japonês ou toyotista. Ao desconstruir a rigidez do modelo fordista, o toyotismo tem como premissa básica a flexibilidade do aparato produtivo e da organização do trabalho. A lógica imperante passa a orientar-se com base na horizontalização das atividades; a fábrica começa a delegar diversas fases da produção às empresas terceirizadas e subcontratadas. O resultado é a redução dos cargos e funções, a desconexão do empregado à tomadora de serviços, com a precarização das garantias juslaborais, e a mitigação gradativa das verdadeiras práticas sindicais (ANTUNES, 2015).

Diante desse quadro, cuja reestruturação produtiva vem provocando intenso enfraquecimento da relação de emprego regular em escala global, a informalidade laborativa surge como alternativa à pessoa despossuída de recursos materiais, representando sensível estratégia de sobrevivência da "classe-que-vive-do-trabalho" (ANTUNES, 2015, p. 33).

A heterogeneidade desse fenômeno pode ser identificada em pesquisas já realizadas sobre o tema, tanto em trabalhos empíricos como teóricos. Consoante bem assinalado por Vargas (2016), não há, na quadra atual, consenso entre os estudiosos sobre a adequada definição da informalidade laborativa; ao contrário, proliferam-se variados conceitos, a partir 
de distintas perspectivas. Defende, a autora, um enfoque multidisciplinar, em virtude dos inúmeros aspectos socioeconômicos que envolvem a temática.

Noronha (2003), por sua vez, ao fazer crítica da percepção da informalidade no contexto brasileiro, aponta três grandes matrizes de abordagem conceitual desse modelo de ocupação. A primeira, dos economistas, se concentra no binômio formal-informal; a segunda, dos juristas, se apega ao que é legal e ilegal; e a última, do senso comum, toma por base as noções do que é justo e injusto. O autor, assim, reconhece que, para a compreensão da informalidade laborativa, é necessário o envolvimento de distintos campos de saber.

De igual modo, Amaral, Druck e Filgueiras (2004), ao discutirem o conceito de informalidade laborativa, a partir da Economia e da Sociologia do Trabalho, ressaltam a multiplicidade de significados aplicados ao fenômeno, sempre dependente da perspectiva teórica e dos objetivos específicos de cada estudo.

Diante dos variados enfoques que tangenciam à informalidade laborativa, revela-se fundamental, nessa ordem de ideias, a construção de um conceito interdisciplinar. A abordagem interdisciplinar faz-se necessária em face de específica preocupação concreta; ou seja, da constatação da existência de singular processo social, cuja explicação não se mostra suficiente se tomarmos como base apenas um ramo de conhecimento.

Noutras palavras, o processo epistemológico da interdisciplinaridade se baliza, essencialmente, no diálogo entre diferentes campos de saber, propondo, assim, inovadora e complementar perspectiva metodológica. Aproveitando-se das especificidades de cada disciplina, tem por escopo interpretar e resolver os questionamentos oriundos de preocupações concretas, com imersão no cotidiano. Procura operar nas zonas fronteiriças das disciplinas, religando-as, para responder à complexidade do fenômeno tratado (ALVARENGA et al., 2011).

Aludido modelo de produção de conhecimento também foi defendido por Santos (2007) como o caminho à reconstrução da epistemologia moderna do ocidente. Sugere, nessa perspectiva, a integração das variadas formas de conhecimento ao que se convencionou denominar de saber científico - a 
"ecologia de saberes" (SANTOS, 2007, p. 85). A interdisciplinaridade, nessa linha, operando nas interseções das disciplinas e afastando-se da abstração característica da proposta disciplinar, invoca o pesquisador à imersão no cotidiano das práticas, à consideração da complexidade do espaço vivido, aproximando-se, assim, da real compreensão do que realmente acontece.

Ao considerarmos a atualíssima preocupação concreta que vem desestabilizando a realidade socioeconômica global, relativamente à eclosão da pandemia do novo coronavírus (Covid-19), podemos perceber a relevância da temática proposta neste ensaio. A informalidade laborativa ganhou destacado espaço nos órgãos de imprensa, bem como tornou-se alvo de ações emergenciais do Governo Brasileiro, todas voltadas à mitigação da grave crise de saúde pública. Os trabalhadores informais, principalmente os autônomos, constituem grupo social sobremaneira vulnerável aos efeitos da Covid-19, tanto pelo potencial risco de contágio (exercem as atividades em espaços públicos) quanto pelo caráter incerto dos rendimentos (dependem da livre circulação de pessoas). O estudo aprofundado da informalidade laborativa, sob a ótica interdisciplinar, oferece os substratos teóricos necessários à compreensão das reais demandas daqueles sujeitos em momentos de profunda desestabilização social e estresse econômico.

O presente artigo, então, tem por objetivo apresentar as variadas definições aplicadas à informalidade laborativa, a partir dos campos do Direito, da Economia e da Sociologia. Em seguida, uma vez identificados os pontos de convergência em cada campo de conhecimento, propõe-se a integração conceitual. Por fim, construímos análise do conceito integrado da informalidade laborativa em cotejo com a Lei $n^{\circ}$ 13.982, de 02 de abril de 2020 (BRASIL, 2020), que criou o auxílio emergencial aos trabalhadores diretamente afetados pela crise de saúde pública decorrente da Covid-19.

\section{A INFORMALIDADE LABORATIVA NA ÓTICA DA JURIDICIDADE}

Antes de analisarmos o conceito de informalidade laborativa adotado pelo Direito, revela-se de fundamental importância, neste ensaio, compreender o que esse específico campo de conhecimento entende sobre o valor trabalho. 
Delgado, G. (2012, apud BATAGLIA, 1958) destaca o caráter polissêmico do trabalho, tratando-se de conceito complexo que suscita os mais variados aspectos da vida. Constitui objeto de estudo de diversos ramos de saber, de modo que, cada qual, a depender da abordagem, o situa como elemento central ou subsidiário, mas sempre digno de interesse.

O trabalho, na perspectiva do Direito, é entendido como o negócio jurídico firmado entre o prestador e o tomador, mediante o qual se estabelece a realização de determinada atividade lícita, nos termos do artigo 104 da Lei $n^{\circ}$ 10.406, de 10 de janeiro de 2002 (BRASIL, 2002). Incluem-se, nessa relação, diversas modalidades contratuais, como, por exemplo, a prestação de serviços autônomos, a empreitada, o trabalho voluntário e o vínculo empregatício (GAGLIANO; PAMPLONA FILHO, 2010).

O valor social do trabalho no constitucionalismo brasileiro é elevado a fundamento republicano, afigurando-se no mesmo status jurídico atribuído à livre iniciativa, nos termos do artigo $1^{\circ}$, inciso IV, da Constituição Federal de 1988 (BRASIL, 1988). De igual modo, a Ordem Econômica idealizada na Carta Política, à luz do art. 170, caput (BRASIL, 1988), toma por base a valorização do trabalho humano e da livre iniciativa, com o desiderato de assegurar-se a todos existência digna, conforme os ditames da justiça social. Se não bastasse, a Ordem Social fundamenta-se, também, no primado do trabalho, consoante o art. 193 da Constituição Federal de 1988 (BRASIL, 1988).

Observe-se que o Poder Constituinte, ao erigir, ao lado da livre iniciativa, o trabalho como princípio republicano fundamental e conformador das ordens econômica e social, sinaliza para a implantação do Estado Social; ou seja, modelo de sociedade comprometido em assegurar aos trabalhadores os direitos fundamentais, integrando-os, como cidadãos, ao quadro políticoinstitucional vigente (MEIRELES, 2008).

Nesse sentido, Delgado, G. (2015) esclarece que o trabalho, no ordenamento jurídico pátrio, situa-se em posição normativa e axiológica diferenciada, intimamente atrelado ao princípio da dignidade da pessoa humana, consoante o art. 1 $^{\circ}$, inciso III, da Constituição Federal de 1988 (BRASIL, 1988); do qual se extrai a necessidade de concretização, no plano 
social, do intitulado "direito fundamental ao trabalho digno" (DELGADO, G., 2015, p. 27).

Vale destacar que o princípio constitucional da dignidade da pessoa humana traduz-se em axioma que ilumina e orienta toda a atividade interpretativa da legislação brasileira. Sobressai-se, no aspecto, como valor intrínseco ao ser humano, que lhe atribui autonomia para decidir sobre os mais variados projetos de vida e para posicionar-se, no corpo social, inclusive perante o Estado, como legítimo sujeito de direitos. Para Sarlet (2011, p. 73), referido princípio assim pode ser definido:

\begin{abstract}
A qualidade intrínseca e distintiva reconhecida em cada ser humano que o faz merecedor do mesmo respeito e consideração por parte do Estado e da comunidade, implicando, neste sentido, um complexo de direitos e deveres fundamentais que assegurem a pessoa tanto contra todo e qualquer ato de cunho degradante e desumano, como venham a lhe garantir as condições existenciais mínimas para uma vida saudável, além de propiciar e promover sua participação ativa e corresponsável nos destinos da própria existência e da vida em comunhão com os demais seres humanos, mediante o devido respeito aos demais seres que integram a rede da vida.
\end{abstract}

A dignidade da pessoa humana atua como cláusula generalizante que delimita o espaço de integridade moral garantido a todos os sujeitos pela simples existência. Barroso (2009), nessa linha, esclarece que o multicitado axioma encerra quatro elementos nucleares que constituem o intitulado mínimo existencial, a saber: renda mínima, saúde básica, educação fundamental e acesso à Justiça.

Fácil perceber, então, que o percurso para que o ser humano possa alcançar esse patamar de dignidade deve, necessariamente, passar pelo trabalho. É justamente por meio da atividade laborativa que a pessoa, uma vez despossuída de outros recursos materiais, consegue obter a renda mínima e, com isso, ver razoavelmente assegurados os demais direitos sociais previstos no art. $6^{\circ}$ da Constituição Federal de 1988 (BRASIL, 1988).

Ao lado da alta carga valorativa que a ciência jurídica atribui ao trabalho, é certo, também, que o referido ramo de conhecimento tem, por pressuposto fundamental, o paradigma da legalidade. Segundo Ferreira Filho (2007), as leis cumprem, no Estado de Direito, duas finalidades; a primeira, delimitar a liberdade dos indivíduos para que seja possível a convivência em 
sociedade; a segunda, estipular os limites da atuação dos órgãos estatais, a fim de obstaculizar o arbítrio.

$\mathrm{O}$ art. $5^{\circ}$, inciso II, da Constituição Federal de 1988, estabelece, como garantia fundamental, que "ninguém será obrigado a fazer ou deixar de fazer alguma coisa senão em virtude da lei” (BRASIL, 1988). Se, por um lado, assegurada a liberdade ao sujeito de direito, por outro, tal garantia encontra limite na lei.

Percebe-se que a informalidade laborativa, desde que não remeta a atividades criminalmente condenáveis, afigura-se como o modelo de ocupação que garante à pessoa, minimamente, o direito fundamental ao trabalho digno; outrossim, entra em oposição ao princípio da legalidade, já que, para o direito, a informalidade pressupõe aquilo que não se encontra abarcado pelo ordenamento jurídico.

A informalidade laborativa, para o Direito, provoca, por assim dizer, espécie de crise no sistema, cisão dos parâmetros de contratação laborativa normativamente estabelecidos. Anomalia jurídica inexorável, atuante em profusão no espaço vivido, que entra em confronto, inevitavelmente, com o paradigma da legalidade, nos movimentos de tensão e de resistência pelo direito ao trabalho.

A relação de emprego assalariada, com formalização em Carteira de Trabalho, está devidamente regulamentada, tanto na CRFB (BRASIL, 1988), passando pela Consolidação das Leis do Trabalho (CLT) - Decreto-lei $\mathrm{n}^{\circ}$ 5.452, de $1^{\circ}$ de maio de 1943 (BRASIL, 1943), e alterações subsequentes - e pela legislação esparsa trabalhista, quanto nos instrumentos de negociação coletiva. Esse corpo normativo tem por escopo concretizar, no plano fático, nas palavras de Delgado, M. (2016, p. 54), a "melhoria das condições de pactuação da força de trabalho na ordem socioeconômica". Reequilibrar no plano jurídico o que é reconhecidamente desigual na órbita factual.

O trabalho por conta própria, de igual modo, para o seu regular desenvolvimento, conta com regras específicas, atinentes à formalização do trabalho autônomo e instrumentos legais de registro de pessoa jurídica.

Com o advento da Lei $n^{\circ}$ 9.876, de 26 de novembro de 1999 (BRASIL, 1999), que incluiu a alínea "h" no inciso $V$ do art. 12 da Lei $n^{\circ} 8.212$, de 24 de 
julho de 1991 (BRASIL, 1991), o trabalhador autônomo passou a figurar, na seara previdenciária, como contribuinte individual - segurado obrigatório da Previdência Social. O referido dispositivo considera, como tal, "a pessoa física que exerce, por conta própria, atividade econômica de natureza urbana, com ou sem fins lucrativos" (BRASIL, 1991). Para o regular exercício dessa ocupação, a Lei nº 8.212/91 (BRASIL, 1991), no art. 21, estabelece a obrigação de recolhimento das contribuições previdenciárias, instrumento essencial para viabilizar o acesso aos benefícios garantidos pela Previdência Social.

A seu turno, o trabalho por contra própria, constituído sob a forma de microempresa (MEI), encontra-se regulamentado pela Lei Complementar $n^{\circ}$ 123/2006 (BRASIL, 2006), cujo art. 18-A estabelece a possibilidade de criação do modelo de pessoa jurídica consubstanciado no MEl. Ao propor o sistema simplificado e menos oneroso de recolhimento de impostos e contribuições, a referida lei tem por desiderato incentivar a formalização de certas atividades "acesso à formalidade registral" - e a consequente inserção dos sujeitos ao sistema de Seguridade Social (NUNES, 2013, p. 32).

$\mathrm{O}$ ordenamento jurídico brasileiro, orientando-se pelo paradigma da legalidade, assume a preocupação singular de normatizar $\circ$ trabalho em sociedade, deixando antever que são irregulares todas as atividades laborativas que não se conformam aos parâmetros estabelecidos. Para a ciência jurídica, a implementação plena do direito fundamental ao trabalho digno deve passar, a rigor, pelo enquadramento legal das ocupações. Nessa ótica, pode-se dizer que a informalidade se apresenta como algo estranho ao sistema, infenso ao Direito.

Segundo Noronha (2003, p. 112), a matriz conceitual da informalidade, na perspectiva dos juristas, concentra-se na oposição entre o "legal" e o "ilegal". Esclarece o autor, no aspecto que, no Brasil, considera-se como formal: o trabalho assalariado inscrito em documento profissional; o trabalhador autônomo registrado; ou aqueles, que, constituídos em empresa, assumem a condição de empregadores. Chama a atenção, o autor, também, para a intitulada "informalidade jurídica" (NORONHA, 2003, p. 119), segundo a qual a sua recorrência se deve à excessiva liberdade do mercado de trabalho quanto à regulamentação das relações laborativas; fato que inviabilizaria a atuação 
estatal na asseguração de garantias mínimas no âmbito dos contratos de emprego.

A Organização Internacional do Trabalho (OIT) (2006), na mesma linha, utilizando-se do termo economia informal para cunhar a informalidade laborativa, define esse fenômeno como a forma de ocupação que não encontra amparo na legislação. Os trabalhadores, nessa condição, a depender da atividade, atuam em diferentes graus de interação com a lei, desde os que operam às margens das normas estatais, sem qualquer registro perante 0 Estado, até os que, embora formalizados, atuam, na prática, sem observância ao que está disposto na legislação, por considerá-la "inadequada, gravosa ou impor encargos excessivos" (OIT, 2006, p. 7).

De igual modo, Costa (2010) associa a informalidade laborativa ao complexo de atividades que, de certa maneira, não atende aos padrões de contratação estabelecidos em lei, de modo que os sujeitos, nessa condição, permanecem alijados de qualquer representação coletiva. Destaca, nesse sentido, que a informalidade é definida pelo "método da negação" (COSTA, 2010, p. 182); ou seja, referida atividade se identifica como aquela que não se encontra regulada pelo Estado de Direito.

Questão instigante a ser considerada nessa temática traduz-se na postura que os serviços de fiscalização do Estado assumem diante das práticas laborativas informais. Essa problemática foi observada por Cunha (2007), ao pesquisar sobre a lógica de apropriação dos espaços públicos pelo comércio popular, no Centro Histórico da cidade de Fortaleza-CE. A autora defende a tese de que o comércio popular promove, naquele contexto, um singular processo de redefinição dos espaços públicos como uma espécie de "contra-uso" (CUNHA, 2007, p. 18). Os comerciantes de rua, ao se estabelecerem nas calçadas e vias de acesso, subvertem os usos esperados desses lugares, transformando-os em locais de trabalho. Foi identificado que os trabalhadores se dividiam entre os cadastrados, detentores de alvará de licença, e os não cadastrados. Os licenciados não enfrentavam maiores embates com os fiscais do Município. Entretanto, os trabalhadores sem licença submetiam-se a uma política de tolerância, caracterizada por conchavos e favores com os agentes públicos. Se a rarefeita sintonia daquelas alianças 
fosse desestabilizada, os fiscais assumiam postura sumamente repressiva, com ações violentas, apreendendo as mercadorias dos ambulantes.

Veja-se que o Poder Público, reconhecidamente incapaz de aplicar, na concretude, o princípio da legalidade, e relegando ao oblívio a sua atividade coercitiva, confere à informalidade laborativa um singular status de ilegalidade tolerada. A informalidade, nesse contexto, nas palavras de Soto (1987, p. 46), opera numa "zona de penumbra [...] que tem uma extensa fronteira com o mundo legal e onde os indivíduos se refugiam quando os tributos para cumprir as leis excedem seus benefícios". Percebe-se, na dinâmica das práticas informais, sob o prisma do Direito, certo locus fugidio em que a não aplicação da lei é o bastante para conferir àquele grupo e à sociedade um mínimo de pacificação social.

\section{CENTRALIZANDO O TEMA NA PERSPECTIVA ECONÔMICA}

A abordagem econômica apresenta contribuições teóricas fundamentais à compreensão da informalidade laborativa. Cacciamali (1982, p. 37), citando o economista Hans Singer (1978), destaca que a "o setor informal é como uma girafa, difícil de descrever, mas fácil de reconhecer".

Estudo pioneiro sobre a temática foi capitaneado no final da década de 1960 e início da década de 1970 pelo antropólogo econômico Keith Hart (1973), para o qual se confere a idealização do termo "setor informal" (VIANA, 2006, p. 15).

Com efeito, Hart (1973) desenvolveu pesquisa sobre as experiências de um grupo de migrantes do norte de Gana, os Fafra, que se deslocaram para a cidade de Accra, situada ao sul do país. Constatou-se que, em virtude das precárias condições de trabalho e de renda ali encontradas, as atividades informais representavam importante alternativa aos indivíduos apartados do mercado de trabalho formal. Nesse contexto, ao lado das ocupações regulares, a informalidade constituía meio adicional de auferir rendimentos pelo subproletariado, cujos efeitos não poderiam ser ignorados pelos economistas. O autor, então, percebendo a importância dessa atividade para a conformação daquele grupo social, traduzindo-se como elemento amortecedor de choques 
em face do desemprego, cunhou referido fenômeno como o "setor informal" (HART, 1973, p. 68). Expressão que traduz todo o complexo de atividades e de operações econômicas marginais, cujos indivíduos, com regularidade, se dedicam com o intuito de auferir ou complementar os rendimentos.

Amaral, Druck e Filgueiras (2004) trazem perspectiva aprofundada sobre os esforços empreendidos para a adequada definição da informalidade laborativa. Chamam à atenção que o conceito deve ser claramente explicitado, de sorte que, dada a diversidade das definições existentes, "podem mais confundir do que facilitar a compreensão da estrutura e dinâmica do mercado de trabalho" (AMARAL; DRUCK; FILGUEIRAS, 2004, p. 211). Os autores destacam a existência de três matrizes conceituais que servem para demarcar o espaço da informalidade:

\footnotetext{
1) o que tem por critério a forma de organizar a atividade econômica (capitalista / não capitalista), que dá origem a dois setores (formal $\mathrm{x}$ informal), 2) o que tem por critério a natureza jurídica da atividade econômica (legal ou ilegal) que demarca dois tipos de fenômenos (economia registrada x economia subterrânea) e 3) o que junta os dois critérios anteriores, dando origem a dois segmentos (atividades fordistas ou capitalistas registradas $\mathrm{x}$ atividades não-fordistas). (AMARAL; DRUCK; FILGUEIRAS, 2004, p. 211)
}

O primeiro conceito, segundo os autores, foi construído no âmbito do relatório de emprego e renda no Quênia, publicado pela OIT em 1972. Associa a informalidade ao excedente de mão de obra não absorvido pelo mercado de trabalho formal em países subdesenvolvidos. Fato que conduziu os trabalhadores a procurarem alternativas em ocupações de baixa produtividade, apartadas do regime de emprego assalariado. Referida proposição foi alvo de críticas por reduzir a informalidade laborativa à simples antítese do mercado de trabalho formal. E mais, por associá-la, tão somente, às parcelas desfavorecidas da população.

Em que pese a natureza jurídica, o segundo conceito revela determinantes econômicos interessantes para essa discussão. Como não poderia ser diferente, a definição parte do pressuposto de que a informalidade laborativa seria uma atividade econômica ilegal ou ilícita, já que não abarcada pela legislação. Estaria, nessa perspectiva, atrelada à econômica subterrânea; ou seja, aquela que opera, no espaço vivido, às margens das normas estatais. 
Não se considera a informalidade como setor da economia, na medida em que as práticas informais podem acontecer tanto em empresas não registradas quanto nas formalizadas, desde que haja descumprimento das regras jurídicas (AMARAL; DRUCK; FILGUEIRAS, 2004). Há a superação da dicotomia simplista entre o setor formal e o informal.

O terceiro conceito defende a junção dos anteriores, considerando tanto as atividades e formas de produção não capitalistas (trabalho por conta própria) quanto as relações de emprego não registradas (empregados sem carteira assinada). Também chamado de não-fordista, esse conceito se associa a todos os modelos de ocupação entendidos como precários, já que as práticas informais, assim consideradas, não assegurariam o estuário de garantias tutelares previsto na legislação (AMARAL; DRUCK; FILGUEIRAS, 2004).

Interessante notar o grau de complexidade na construção do conceito para a informalidade. Percebe-se, nitidamente, o caráter interdisciplinar desse fenômeno, uma vez que o Direito tangencia à análise da Economia; relega à economia subterrânea todas as atividades apartadas do padrão oficial de contratação laborativa.

Exemplo disso é a pesquisa desenvolvida por Soto (1987, p. 3), que se aprofunda na realidade da chamada "Economia Subterrânea" do Peru. O autor vai além das específicas dinâmicas laborativas desenvolvidas pelos informais. Considera, como economia subterrânea, além das práticas do comércio informal e do transporte informal, as estratégias adotadas pelos sujeitos na constituição de habitações informais. Essa economia subterrânea, para a produção de efeitos no mercado de trabalho, como a criação de emprego e de renda, opera, segundo o autor, com base na "normatividade extralegal" (SOTO, 1987, p. 47). Estratégia singular adotada pelos informais para fazer valer, em prejuízo do direito oficial, as regras por eles próprios estabelecidas, isso para que se potencie as atividades econômicas subterrâneas presentes em profusão naquele corpo social, desde a aquisição de imóveis até a ocupação econômica inoficiosa dos espaços.

Para Noronha (2003), a abordagem econômica revela-se como uma das matrizes conceituais fundamentais da informalidade. Aponta três 
perspectivas na compreensão dessa temática: a) Velha Informalidade, que corresponde ao surgimento de subempregos em face do desinteresse do investimento capitalista em países subdesenvolvidos; b) Informalidade Neoclássica, cuja expansão é provocada pelo natural impulso lucrativo das empresas sediadas em países com excessiva regulamentação trabalhista; c) Nova Informalidade, que decorre das profundas transformações no mundo do trabalho, cuja horizontalização das atividades empresariais geram estratégias de subcontratação e de terceirização, com diminuição da força atrativa do emprego regular assalariado.

As aludidas abordagens indicadas por Noronha (2003) sugerem, em olhar superficial, a evolução histórica da questão da informalidade. Entretanto, é certo que referidos enfoques, na quadra atual, se manifestam simultaneamente no espaço econômico, ainda mais se levarmos em conta a realidade dos países em desenvolvimento.

O pensamento de Cacciamali (1982) defende perspectivas teóricas, no campo da Economia, essenciais à compreensão das dinâmicas da informalidade laborativa. Concebe o setor informal como o modo de organização da produção que se interpenetra, de forma intersticial e subordinada, no interior da produção capitalista. Referido segmento seria constituído por produtores informais autônomos, não subsumidos à relação de emprego assalariada, que, na posse dos meios de produção, orientam suas atividades com o auxílio do trabalho familiar ou de alguns ajudantes.

O setor informal, nessa perspectiva, reuniria as seguintes características: a) produção sob a forma simultânea de patrão e empregado; b) conjugação das atividades de produção com as de gestão; c) rendimentos obtidos são direcionados à manutenção familiar e da atividade econômica, e não para a acumulação; d) atividade não é orientada para uma taxa de retorno competitiva, mas pelo fluxo de renda que fornece ao trabalhador; e) utilização de mão de obra familiar, inexistindo liame impessoal ou de mercado entre os que trabalham no negócio; f) trabalhador participa e toma ciência de todo o processo de trabalho (CACCIAMALI, 1982).

A informalidade laborativa, segundo a autora, estaria intimamente vinculada, em posição subordinada, aos movimentos de expansão e 
reprodução capitalista, uma vez que o "seu espaço se reduz e se amplia e sua composição se altera em função do quadro e do caminho do desenvolvimento econômico-social" (CACCIAMALI, 1982, p. 29). Em outras palavras, essa subordinação é ditada por movimentos assimétricos na conformação do mercado de trabalho. Ao toque da produção capitalista, a informalidade laborativa, em determinado lugar, pode ser extinta, e noutro, recriada, sempre dependente das dinâmicas das grandes empresas sobre o espaço econômico.

O espaço econômico da informalidade laborativa é, por essência, intersticial, caracterizado pela inconstância, e permanentemente redefinido, atuando, os trabalhadores, em lugares abandonados economicamente ou ainda não explorados pelas empresas. A produção capitalista, ao avançar sobre determinado espaço econômico, delimita simultaneamente o interstício que, em dado momento, pode ser aproveitado pela informalidade. Interstício que, no quadro seguinte, pode ser redefinido, à medida que as firmas capitalistas enxerguem algum proveito lucrativo no espaço econômico ora ocupado pela informalidade.

Esse espaço intersticial revela, nessa abordagem, duplo caráter: de um lado, levam os sujeitos, uma vez apartados do mercado de trabalho formal, a procurarem, por conta própria, espaços econômicos ainda não explorados pelas empresas; de outro, estabelecidos nesses espaços econômicos, os trabalhadores ficam subordinados aos avanços da produção capitalista, levando-os à redefinição constante desses espaços apropriados, que podem ser extintos ou recriados ao talante das estratégias das firmas do setor formal.

Percebe-se, assim, nítida distinção teleológica concernente aos movimentos de ocupação dos espaços econômicos. Enquanto as firmas capitalistas dominam os espaços tendo por precípua finalidade a obtenção de lucro, a informalidade laborativa, de um modo geral, apropria-se dos interstícios, dos lugares ainda inexplorados pelas empresas, como estratégia de subsistência.

\section{A INFORMALIDADE LABORATIVA SOB O PRISMA DA SOCIOLOGIA}


$\mathrm{Na}$ esteira do mesmo roteiro adotado na abordagem jurídica, interessa compreendermos, a priori, o significado que a Sociologia confere ao valor trabalho.

Afastando-se da perspectiva estritamente sociológica, mas, ao mesmo tempo, resgatando o significado do valor trabalho - filosoficamente apreendido - que serviu como importante base à formulação teórica do ramo de conhecimento em discussão, indispensável, inicialmente, servirmos das contribuições hegelianas.

Segundo Busch (2005), o ponto comum entre os intérpretes do pensamento de Hegel repousa no fato de que este eminente filósofo alemão foi pioneiro na compreensão do valor trabalho como o ato de exteriorização do sujeito. Essa exteriorização, segundo Busch (2005), é concebida por Hegel como a realização de determinada atividade intencional, estabelecida pelo próprio sujeito, a fim de executar dado objetivo. O trabalho, na abordagem hegeliana, consistiria na ação intencional, protagonizada pelo sujeito, que, exteriorizando-se, faz de si mesmo, internamente, um objeto.

A teoria hegeliana toma como ponto fundamental, para a idealização do valor trabalho, o ato de estrita autonomia de vontade do sujeito, cuja atividade empreendida é firmada em específico objetivo. Daí porque, segundo Busch (2005), a concepção do trabalho desenvolvida por Hegel se afasta daquele tipo de atividade laborativa imperante na economia capitalista. A uma, porque, no modo capitalista de produção, o trabalho não serve para atender às necessidades tradicionais, mas volta-se estritamente à obtenção de lucro. A duas, porque a pessoa, enquanto portadora do trabalho, é concebida como mero objeto, excluindo-se, de si, toda a iniciativa pessoal; ou seja, a rigor, não há a exteriorização.

A concepção hegeliana sobre o trabalho, serviu como subsídio à teorização de Marx (1996). Importante pontuar, entretanto, que a teoria marxista se concentra num específico modelo de ocupação laborativa: o trabalho assalariado imperante na época capitalista (SPURK, 2005). Com efeito, Marx (1996), partindo da noção de que o trabalho é uma forma de exteriorização do sujeito, defende que o homem, agindo assim, ao mesmo tempo em que modifica a natureza externa, acaba alterando a sua própria 
natureza. Entende que o trabalho, enquanto gerador de valores de uso, afigurase como elemento essencial à existência humana, já que proporciona o intercâmbio com a natureza, na produção de recursos vitais à sobrevivência.

Todavia, no âmbito das relações capitalistas de produção, segundo Marx (1996), opera-se verdadeira subversão da ideia do trabalho. A força de trabalho, para o capitalista, é entendida como mercadoria, uma atividade que tem, como substrato material, a produção de valores de troca, em vez de valores de uso. No pensamento de Marx (1996), o capitalista compra a força de trabalho - contrata o trabalho assalariado -, integrando esse elemento vivo aos outros elementos mortos - maquinários e demais instrumentos de trabalho ambos constituindo, na mesma unidade, os fatores de produção. No interior das firmas capitalistas, os valores de uso produzidos pelos sujeitos, por intermédio do trabalho, não mais lhes pertencem, mas são destinados ao capital no processo de criação de valores de troca e, por conseguinte, da maisvalia.

Segundo Spurk (2005, p. 203), a teoria marxista revela "uma contradição profunda entre, de um lado, a durabilidade, a estabilidade e a solidez do capital e, de outro, a fragilidade, a incerteza dos trabalhadores”. Esclarece que essa relação assimétrica aparece como fator essencial nesse sistema, na medida em que a disponibilidade dos trabalhadores, enquanto meros fatores de produção, reafirma as exigências sempre mutáveis da lógica do capital.

Não se pode olvidar que o trabalho ocupa, atualmente, posição de destaque na estruturação da sociedade, mormente ao levarmos em consideração os sujeitos despossuídos de recursos, como é o caso dos que se dedicam à informalidade laborativa. Presenciamos, na quadra atual, um movimento de profícua criação de novas formas de ocupação, cujas bases de contratação, no entanto, são marcadas pela precarização, nos diversificados modos de subcontratação, de terceirização e de informalidade (ANTUNES, 2015).

Antunes (2009) pontifica que o trabalho constitui-se em categoria intermediária que viabiliza, nos atos de mediação com a natureza, a transformação do homem em ser social. Esclarece que o trabalho está "no 
centro do processo de humanização do homem", já que viabiliza, nos movimentos de intermediação, a satisfação das necessidades vitais de reprodução social (ANTUNES, 2009, p. 136). Ressalta o caráter finalístico do valor trabalho, no sentido de que é impulsionado sempre, e previamente, a partir da objetividade gerada na práxis.

Aludido autor, na esteira do pensamento marxiano, defende que o trabalho, enquanto elemento intrínseco ao ser humano, passou por profundas transformações com o surgimento do sistema de capital. Inicialmente, o trabalho era concebido como a atividade que se orientava à preservação das funções vitais de reprodução individual e social, o que se implementava sem parâmetros hierárquicos de dominação ou de subordinação. Com o surgimento do sistema de capital, desenvolveu-se, no seu interior, completa subordinação estrutural do trabalho ao capital, retirando do sujeito trabalhador a condição apriorística de produção de valores de uso nos movimentos de intermediação com a natureza. Fato que provocou a degradação do sujeito real da produção, de maneira que o trabalho, para o capital, passou a atuar como mero fator material - "objetividade reificada" (ANTUNES, 2009, p. 27).

Esse movimento de subordinação estrutural do trabalho ao capital, gestado no âmbito da produção capitalista, encontrou sua fase mais dramática a partir da década de 1980. Para Antunes (2015), nos anos posteriores àquele marco, a "classe-que-vive-do-trabalho sofreu a mais aguda crise deste século, que atingiu não só a sua materialidade, mas teve profundas repercussões na sua subjetividade", afetando, em última análise, a sua própria "forma de ser" (ANTUNES, 2015, p. 33).

A partir da década de 1970, com o avanço das políticas neoliberais adotadas pelos países economicamente avançados, surge, em substituição ao fordismo, o sistema de produção toyotista ou japonês. Desconstruindo a fixidez do antigo regime, o toyotismo assume, como pedra de toque, a intensa flexibilização da organização do trabalho e das dinâmicas produtivas, passando a operar sob uma lógica horizontalizada. Ao contrário da configuração piramidal outrora adotada pelo fordismo, o modelo japonês apregoa a estruturação reticular da produção, delegando diversas atividades e serviços às empresas subcontratadas ou terceirizadas (ANTUNES, 2015). 
O quadro mais perverso deflagrado com a implantação dessa política produtiva traduz-se na disseminação, em escala globalizante, do desemprego estrutural. Para ilustrar, segundo Antunes (2015), nos anos 1940, a Europa Ocidental contava com efetivo de trabalhadores atuantes na indústria na ordem de $40 \%$ (quarenta por cento) da população economicamente ativa. Nos anos 1990, esse contingente não passava dos 30\% (trinta por cento), havendo projeções de que, neste século, diminuirá para $20 \%$ (vinte por cento) a $25 \%$ (vinte e cinco por cento).

No Brasil, os efeitos dessa reestruturação produtiva foram mais intensamente sentidos nos anos 1990. A abertura econômica iniciada no Governo Collor, que culminou com a implantação do Plano Real no Governo Itamar, alinhados às reformas neoliberais protagonizadas, em seguida, pelo Governo Fernando Henrique Cardoso, nas palavras de Malaguti (2000, p. 44), promoveram a "subordinação irrestrita da soberania nacional ao Mercado e aos ditames das instituições internacionais do comércio".

Não por coincidência, a década de 1990 foi o cenário de uma das piores crises de desemprego na sociedade brasileira. Por exemplo, consoante Malaguti (2000, p. 64), "de outubro de 1996 a outubro de 1997, o desemprego cresceu mais de $20 \%$ (vinte por cento) nas seis principais regiões metropolitanas do país". Prossegue o autor informando que, em Salvador, a taxa de desemprego, naquele período, saltou para mais de $28 \%$ (vinte e oito por cento), ao passo que, em Belo Horizonte e em São Paulo, 19\% (dezenove por cento).

Essas medidas socioeconômicas implantadas no âmbito dos processos produtivos, que foram legitimadas e até incentivadas pelo Estado, como políticas públicas, provocaram, no interior da classe trabalhadora, o "processo de maior heterogeneização, fragmentação e complexificação" (ANTUNES, 2015, p. 62). Ao mesmo tempo em que houve o recrudescimento dos empregos formais na indústria, operou-se o aumento do chamado subproletariado. Dentre as diversas formas de trabalho precário que compõem essa subproletarização, destaca-se, como não poderia ser diferente, a expressiva massa de trabalhadores atuantes na informalidade laborativa. 
Malaguti (2000) também credita a propagação do fenômeno da informalidade às profundas alterações da estrutura produtiva experimentadas nas últimas décadas. Atingidos pelo desemprego e à falta de rendimentos, com privação de elementares direitos de cidadania, o sujeito não encontra alternativa senão dedicar-se às práticas informais, como expediente de sobrevivência. Qualificando-a como o "refúgio dos sem-opção" (MALAGUTI, 2000 , p. 68), esclarece o autor que a informalidade se apresenta, na quadra atual, como única alternativa aos excluídos, espaço comum frequentado pelas camadas mais fragilizadas da população.

A informalidade laborativa, assim, para a Sociologia do Trabalho, encontrou terreno fértil na esteira das profundas transformações implementadas no mundo do trabalho nos últimos tempos. O simbolismo que sustentava o padrão tradicional assalariado, caracterizado, no modelo fordista, pela estabilidade e pela segurança jurídica, foi substituído, no prisma toyotista, pelo singular processo de "estranhamento" (ANTUNES, 2015, p. 33). Expressão que, segundo Antunes (2015), revela obstáculos sociais que impedem o indivíduo de realizar-se como pessoa, de desenvolver, pelo trabalho, suas capacidades em direção a uma existência cheia de sentido.

Bauman (2001, p. 182) aponta que o contexto histórico dominado pelo regime fordista de produção consistiu na era do "capitalismo pesado", que demarcou a chamada "modernidade sólida". Período em que havia uma certa estabilidade nas relações entre o capital e o trabalho, ao passo que ambos estavam intimamente engajados, numa relação interdependente, na manutenção do status quo. Nessa estruturação, o trabalhador, embora dependente do emprego formal assalariado, reunia plenas condições de criar expectativas a longo prazo; era portador, em suma, de estabilidade, não se justificando a procura por meios alternativos de ocupação.

Com a superação daquele antigo regime produtivo, e a chegada da acumulação flexível e do toyotismo, vivemos, atualmente, segundo Bauman (2001, p. 187), a era do "capitalismo leve", ou da "modernidade líquida". As novas políticas estruturantes do regime de produção então implementado, como já dito, apregoam a flexibilização e a desregulamentação das práticas laborativas, com a criação de contratos temporários e terceirizados, 
provocando o contingente de subproletários marcado pela instabilidade, dramaticamente forçado a criar expectativas a curto prazo.

Sennett (2003, p. 9) reforça a ideia de que a mentalidade de curto prazo imperante no que ele denomina de "capitalismo flexível" acaba por forçar os empregados, constantemente, a migrarem de um emprego para outro, de lugar em lugar. A aversão à rotina, a ausência de uma estrutura de poder bem definida, a valorização da cultura do risco, tudo num contexto em que a estabilidade é encarada com repulsa pelas empresas, levam à corrosão do caráter do indivíduo. Situação que degrada as relações intersubjetivas, tanto fora quanto dentro do local de trabalho, impedindo os trabalhadores ao desenvolvimento de "um senso de identidade sustentável" (SENNETT, 2003, p. 27).

Seja pela ameaça constante do desemprego, seja pelas condições precárias de contratação e de prestação de serviço, o sujeito, sem opção e despossuído de recursos, enxerga a informalidade laborativa como a saída, reação alternativa ao estranhamento provocado por esse ambiente empresarial hostil e superficial.

Aludido fenômeno, para Noronha (2003, p. 119), é concebido, na perspectiva sociológica, como a "informalidade da globalização", no sentido de que as alterações que se concretizaram no mundo do trabalho são creditadas ao crescimento desordenado da concorrência internacional. Os efeitos imediatos seriam a mitigação crescente dos postos de trabalho e o aumento das formas precárias de ocupação (NORONHA, 2003).

De igual modo, Jordão e Stampa (2016), ao estudarem as vivências dos vendedores ambulantes na Região Metropolitana do Rio de Janeiro (RMRJ), observaram que a reestruturação produtiva experimentada no último quartel do século $X X$ serviu como impulso fundamental à eclosão das práticas informais. A partir desse marco temporal, surgiram modelos de ocupação precarizados, sobressaindo-se a informalidade laborativa como alternativa de muitos para o "pertencimento ao mundo do trabalho" (JORDÃO; STAMPA, 2016, p. 81).

O aporte teórico aqui apresentado mostra, inicialmente, que o valor trabalho, na perspectiva sociológica, representa elemento de centralidade na 
experiência dos sujeitos envolvidos em atividades informais. Contudo, os condicionantes que levam o sujeito à informalidade, sobretudo as profundas alterações no mundo do trabalho nas últimas décadas, sugerem que a referida atividade não representa uma opção. Ao contrário, mostra-se como um constrangimento à sobrevivência, um refúgio aos que foram alijados do mercado de trabalho formal ou não enxergam, no emprego registrado, a estabilidade outrora imperante.

\section{A BUSCA PELA INTERDISCIPLINARIDADE: FAZENDO A INTEGRAÇÃO CONCEITUAL}

O próximo passo, nesse percurso interdisciplinar, traduz-se na proposição de um conceito integrado suficiente a descortinar os diversos matizes da informalidade laborativa. Operação metodológica característica da prática interdisciplinar, que se concentra na verificação de pontos de convergência entre distintos marcos teóricos, tomando-se, por referência, as metáforas utilizadas por cada ramo de conhecimento.

As metáforas correspondem, por assim dizer, aos recursos retóricos que dado campo de saber se aproveita para a exploração do fenômeno em estudo. São os elementos linguísticos que se servem das disciplinas, auxiliando a idealização, na forma escrita, de determinado processo social.

No campo do Direito, o paradigma da legalidade orienta a análise da informalidade laborativa. Em que pese o lugar de destaque conferido ao trabalho, como elemento fundamental à concretização, no plano fático, do princípio da dignidade da pessoa humana, a informalidade, a rigor, é vista como algo ilegal, uma crise do sistema normativo. A existência desse fenômeno, para a ciência jurídica, é justificada pela ineficiência do Estado como órgão regulador, bem como pela ausência de políticas públicas tendentes a incluir, em atividades formais, um contingente populacional apartado do universo de direitos.

A seu turno, na perspectiva econômica, o setor informal está intrinsecamente associado ao seu elemento contraposto: o setor formal, entendido como todo o complexo de atividades e operações regulares, que 
invoca o interesse da análise econômica como instrumento garantidor de emprego e renda numa sociedade organizada segundo a lógica capitalista. A informalidade, nessa perspectiva, atua nos interstícios do setor formal, rompendo os padrões prevalecentes de produção, como uma alternativa de sobrevivência aos sujeitos que se encontram impedidos de ingressar em atividades laborativas regulares.

Pode-se inferir que a Sociologia, em enfoque semelhante, associa, também, a informalidade ao seu contraponto - a formalidade. Reconhece, esse ramo de conhecimento, a fundamental importância do valor trabalho como elemento de centralidade que propicia o posicionamento do homem como membro do corpo social. A informalidade laborativa, nesse contexto, seria um fenômeno resultante do constrangimento imposto pelos modos de produção, principalmente a partir da década de 1970, que provocaram o surgimento de formas precárias de ocupação. Impedido de acessar o mercado de trabalho formal, ou premido pelo padrão pouco atraente do emprego assalariado, o indivíduo acaba optando pela informalidade, para assegurar a sua reprodução social.

A primeira interseção identificável entre as disciplinas remete à natureza essencialmente alternativa da informalidade. A Sociologia e a Economia enquadram essa atividade como a antítese das ocupações regulares, em que pese não descartada a sua importância na conformação do mercado de trabalho e da sociedade. O campo do Direito apreende a informalidade como um fenômeno ilegal, que não encontra amparo no ordenamento jurídico, cujo conceito, conforme já esclarecido em linhas pregressas, desenvolve-se a partir do "método da negação" (COSTA, 2010, p. 182).

Outrossim, reputar a informalidade laborativa como fenômeno ilegal, por si só, não parece ser a expressão mais adequada e capaz de abranger todas as formas de ocupação dessa espécie. A ilegalidade, na acepção semântica, representa tanto o que é contrário à lei como o que, por isso, se torna ilegítimo (FERREIRA, 2010). Consoante já esclarecido em linhas pregressas, a informalidade laborativa constitui fenômeno presente em profusão no espaço vivido, sobretudo pela legitimidade que lhe é conferida pelo 
corpo social. Nesse sentido, o próprio Estado, não raras vezes, posiciona-se segundo uma ilegalidade tolerada, o que faz presumir que, a rigor, há uma espécie de reconhecimento oficial da informalidade.

Diante disso, tem-se, aqui, como mais apropriado, reputar a informalidade como um fenômeno alternativo. Ou seja, na acepção semântica, aquilo que existe, e se legitima, independentemente de padrões ou de condutas dominantes (FERREIRA, 2010). Em que pese não abarcado pelo ordenamento jurídico, e figurar como elemento secundário na análise socioeconômica, não se pode olvidar que as atividades informais persistem em nossa sociedade, tanto como um elemento alternativo ao mercado de trabalho formal quanto como alternativa à sobrevivência.

Outro ponto de convergência que aparece na caracterização da informalidade laborativa nas abordagens aqui analisadas constitui-se na constatação de que o sujeito ocupante de atividades informais tem, por premissa básica, assegurar a sobrevivência. Os determinantes socioeconômicos, que provocam a submissão do sujeito em atividade que não encontra amparo no ordenamento jurídico conduzem à ilação de que o principal desiderato é assegurar a própria subsistência e a manutenção familiar. A percepção popular inclusive confirma essa realidade, ao enquadrar as atividades informais como provisórias e orientadas à satisfação de necessidades imediatas (RANGEL, 2017).

A seu turno, o caráter residual da informalidade aparece como ponto de contato entre as disciplinas. O sujeito, de um modo geral, resolve atuar na informalidade orientado a partir de dois determinantes: por não conseguir ingressar no mercado de trabalho formal; e pela condição pouco atrativa do emprego regular assalariado. A ciência jurídica considera ilegais todas as atividades que não encontram revestidas dos padrões de contratação reconhecidos pela lei, sobressaindo-se daí o caráter residual da informalidade.

Isto posto, apresentadas as perspectivas de cada disciplina, bem como os pontos de convergência, possível conceituar a informalidade laborativa como o conjunto de atividades econômicas e profissionais não abarcadas pelo ordenamento jurídico, e desenvolvidas num contexto alternativo e residual ao mercado de trabalho formal, cujas ações dos sujeitos, de um 
modo geral, são toleradas pelo Estado, e orientadas, essencialmente, à garantia de sobrevivência.

\section{A INFORMALIDADE LABORATIVA E O AUXÍLIO EMERGENCIAL: ANALISANDO O CONCEITO INTEGRADO}

Seguindo o roteiro interdisciplinar, cabe, neste subtítulo, descolarmos da perspectiva puramente abstrata até então empreendida, para perquirirmos a adequação do conceito integrado da informalidade laborativa em face de determinado fenômeno. Como já dito, a interdisciplinaridade serve, justamente, para compreendermos os inúmeros processos sociais atuantes no espaço vivido.

Para tanto, importa voltarmos a análise ao auxílio emergencial criado pela Lei $n^{\circ}$ 13.982, de 02 de abril de 2020 (BRASIL, 2020). O benefício foi instituído para amparar parte dos trabalhadores brasileiros em situação de intensa vulnerabilidade aos efeitos da pandemia do novo coronavírus (Covid19).

Nos termos do art. $2^{\circ}$, caput, da referida lei (BRASIL, 2020), o auxílio emergencial foi estabelecido no valor de $\mathrm{R} \$ 600,00$ (seiscentos reais) mensais, com pagamento fixado em três meses - lapso temporal estimado pela norma para a duração da fase mais aguda da crise de saúde pública no território brasileiro (meses de abril, maio e junho de 2020). Segundo os incisos do dispositivo legal, para fazer jus ao benefício, o sujeito deve atender aos seguintes requisitos: a) ser maior de 18 anos de idade; b) não se encontrar em regime formal de emprego; c) não receber do Governo outros benefícios de prestação continuada, à exceção do Bolsa Família; d) contar com renda familiar mensal, por pessoa, de até meio salário mínimo ou com renda familiar mensal total de até três salários mínimos; e) não ter recebido, no ano de 2018, rendimentos tributáveis acima de $R \$ 28.559,70$; f) que atue na condição de microempreendedor individual ou de contribuinte individual ou de trabalhador informal.

À luz do parágrafo $1^{\circ}$ do art. $2^{\circ}$ da Lei $n^{\circ} 13.982 / 2020$ (BRASIL, 2020), o pagamento do auxílio emergencial está limitado a dois membros de cada 
unidade familiar. O parágrafo $3^{\circ}$, por sua vez, estabelece que a "mulher provedora da família monoparental" pode receber duas cotas do auxílio (BRASIL, 2020). O Decreto $n^{\circ} 10.316$, de 07 de abril de 2020, que regulamenta o auxílio emergencial, dispõe, no art. $2^{\circ}$, inciso IV, que a "família monoparental com mulher provedora" corresponde ao "grupo familiar chefiado por mulher sem cônjuge ou companheiro, com pelo menos uma pessoa menor de dezoito anos de idade" (BRASIL, 2020). Da interpretação desses dispositivos, extrai-se que a unidade familiar pode receber, a título de auxílio emergencial, até $R \$$ $1.800,00$ (um mil e oitocentos reais) mensais. O valor máximo deve ser quitado à família monoparental que conte, como provedora, a mulher, e que também integre, nesta unidade, pelo menos um filho maior de dezoito anos. Caso ambos preencham os requisitos legais, receberão o benefício, sendo, para a mulher provedora, o valor de $\mathrm{R} \$ 1.200,00$ mensais, e para o filho maior de dezoito anos, o importe de $\mathrm{R} \$ 600,00$.

Pois bem. O legislador, ao instituir o auxílio emergencial, atento aos gravíssimos efeitos da pandemia da Covid-19, incorreu em notável ineditismo: a categoria dos trabalhadores informais, por lei ordinária federal, foi expressa e oficialmente reconhecida pelo Estado Brasileiro. A alínea "c" do inciso VI do art. $2^{\circ}$ da Lei $n^{\circ} 13.982 / 2020$ identifica, como trabalhador informal, o sujeito "empregado, autônomo ou desempregado, de qualquer natureza, inclusive o intermitente inativo" (BRASIL, 2020).

Cotejando-se a definição legal com o conceito integrado construído no subtítulo pregresso, verifica-se que, de fato, a informalidade laborativa reúne inúmeros modelos de ocupação não abarcados pelo ordenamento jurídico. A expressão de qualquer natureza, constante do dispositivo legal, estampa a impossibilidade de delimitar-se, por lei, o enorme espectro de atuação dos sujeitos que se arvoram em atividades informais.

$\mathrm{E}$ mais, quando o legislador atribui à informalidade esse caráter genérico, fica evidente a concepção de que são atividades alternativas e residuais, quando comparadas às ocupações formais - outro ponto de adequação ao conceito integrado. A natureza residual também é verificada no multicitado dispositivo legal pela expressão desempregado. O legislador optou por enquadrar como informal todo o contingente populacional destituído de 
qualquer forma de ocupação habitual. Ou seja, se o sujeito não é trabalhador autônomo ou não se encontra em regime empregatício, é enquadrado no amplo universo residual da informalidade.

Fica evidente, ainda, pela definição legal, que as atividades informais são toleradas pelo Estado Brasileiro, consoante pontifica o conceito integrado. Atualmente, segundo a Pesquisa Nacional por Amostra de Domicílios Contínua (PNAD), publicada pelo Instituto Brasileiro de Geografia e Estatística (IBGE), em 14 de fevereiro de 2020, relativamente ao $4^{\circ}$ trimestre do ano de 2019 (IBGE, 2020), o Brasil contava com 106,18 milhões de pessoas na força de trabalho, de modo que, deste universo, o total de 11,63 milhões estavam desocupadas. Ainda, ao considerarmos os empregados sem registro em carteira de trabalho, assim como os empregadores e os trabalhadores por conta própria sem inscrição de pessoa jurídica, temos o montante de 39,2 milhões de pessoas atuantes na informalidade, representando, então, 37\% (trinta e sete por cento) da força de trabalho do país.

Isso demonstra a importância das atividades informais para o equilíbrio socioeconômico do Brasil, de modo que, se o Governo deixasse esse vultoso contingente populacional à deriva em plena crise de saúde pública, as consequências sanitárias e do próprio mercado de trabalho tomariam, certamente, proporções bem mais graves. Não obstante a irregularidade das atividades informais perante o Direito, o Estado Brasileiro, atento à realidade dos fatos e premido pela necessidade de dar resposta condizente à pandemia da Covid-19, não apenas tolera, mas passa a reconhecer a informalidade laborativa como relevante modo de ocupação.

Além da expressa definição legal aqui discutida, o reconhecimento da informalidade laborativa perante o Estado Brasileiro aperfeiçoa-se com a criação do auxílio emergencial. A necessidade de pagamento desse benefício ratifica outra característica fundamental da informalidade laborativa, consoante explicitado no conceito integrado: modelo de ocupação orientado, essencialmente, à garantia de sobrevivência.

As atividades informais, como descreve Cacciamali (1982), não são voltadas à acumulação de capital, de modo que os rendimentos são direcionados, basicamente, à manutenção familiar ou do próprio negócio. Deste 
modo, com a necessidade de paralisação das atividades empresariais, por ocasião da crise de saúde pública, parte dos trabalhadores informais viu-se, de forma repentina, sem qualquer rendimento. Cite-se, a título ilustrativo, o Estado de São Paulo que, por meio do Decreto $n^{\circ}$ 64.881, de 22 de março de 2020 (SÃO PAULO, 2020), instituiu a medida de quarentena, restringindo o atendimento presencial ao público em estabelecimentos comerciais e de prestação de serviços, à exceção das atividades essenciais.

Vale registrar, por oportuno, que a situação dos trabalhadores informais se mostra ainda mais alarmante quando não são adotadas as necessárias medidas de quarentena, para isolamento social, em combate à Covid-19. Tomando-se, como exemplo, o comércio informal ambulante, o trabalhador permanece sobremaneira exposto ao contágio, já que exerce atividades em espaços públicos de grande circulação. No caso, pode até receber algum rendimento, mas coloca em risco a própria vida, além de atuar como agente propagador do vírus.

Seja por impeditivo legal, seja pelo receio de contrair a patologia, o trabalhador informal encontra-se privado de exercer, com plenitude, a ocupação que não Ihe proporciona acumulação de capital, mas unicamente meio de subsistência. Aproveitando-se da tutela estatal, enxerga, como solução, o recebimento do auxílio emergencial - último recurso para a satisfação de necessidades vitais básicas.

\section{CONCLUSÃO}

A informalidade laborativa manifesta-se, no cotidiano, como fenômeno heterogêneo, essencialmente complexo, cuja multiplicidade de significados fazse sentida nos discursos acadêmicos, a depender da perspectiva teórica e dos objetivos específicos de cada pesquisa.

A proposta interdisciplinar afigurou-se como o caminho mais seguro, embora desafiador, para apresentar as diversas facetas que envolvem essa temática. Procuramos, assim, aproveitarmos, além da abordagem jurídica, das perspectivas da Economia e da Sociologia. 
Possível conceber que a informalidade laborativa se define a partir de expressões chaves, ou códigos, cujo paradigma da legalidade adotado pelo Direito não se mostra suficiente à sua inteira compreensão. Em vez de reputála como algo ilegal, mais apropriado qualificá-la como um fenômeno alternativo; ou seja, que se legitima, mesmo que não abarcada pelo ordenamento jurídico.

A estratégia de sobrevivência dos sujeitos que se arvoram na informalidade foi identificada como ponto de convergência entre as disciplinas. De igual modo, o seu caráter residual também se apercebeu nos distintos campos de saber, na medida em que os trabalhadores, nessa condição, resolvem atuar, sobretudo premidos pelas condições inacessíveis ou pouco atrativas do mercado de trabalho regular.

Fixadas essas premissas, tornou-se possível construir um conceito interdisciplinar da informalidade laborativa, entendida como o conjunto de atividades econômicas e profissionais não abarcadas pelo ordenamento jurídico, e desenvolvidas num contexto alternativo e residual ao mercado de trabalho formal, cujas ações dos sujeitos, de um modo geral, são toleradas pelo Estado, e orientadas, essencialmente, à garantia de sobrevivência.

O conceito integrado construído, à luz da interdisciplinaridade, mostrouse adequado para interpretar a preocupante situação dos trabalhadores informais em face da pandemia do novo coronavírus.

O auxílio emergencial, recurso disponibilizado pelo governo para mitigar os efeitos da crise, pode representar, de certa forma, reorientação das políticas públicas no tratamento da informalidade laborativa. Da interpretação da Lei $n^{\circ}$ 13.982/2020 (BRASIL, 2020), percebe-se que o Estado Brasileiro passa a reconhecer, oficialmente, a relevância das atividades informais para o equilíbrio do mercado de trabalho. Sensibiliza-se diante da condição de miserabilidade dos sujeitos dedicados a tal ocupação, cujas preocupações são concentradas, basicamente, na satisfação do próprio sustento e da família.

A instituição excepcional de benefício, em situação de urgência sanitária, representa apenas o primeiro passo para a efetiva inclusão dos trabalhadores informais no universo de direitos. A integração à Previdência Social, a instituição de programas educativos com foco na formalização, o oferecimento de linhas de créditos específicas são medidas que, entre outras, 
propiciariam possibilidades aos trabalhadores de criarem expectativas a longo prazo, e, assim, de reunirem melhores condições ao enfrentamento de situações de profunda desestabilização socioeconômica.

\section{REFERÊNCIAS}

ALVARENGA, A. T. de et al. Histórico, fundamentos filosóficos e teóricometodológicos da interdisciplinaridade. In: PHILIPPI JR., Arlindo; SILVA NETO, Antônio J. (Org.). Interdisciplinaridade em Ciência, Tecnologia e Inovação. Barueri: Manole, 2011, p. 3-68.

AMARAL, M. F. do.; DRUCK, G.; FILGUEIRAS, L. A. M. O conceito de informalidade: um exercício de aplicação empírica. Caderno CRH, Salvador, v. 17, n. 41, p. 211-229, mai./ago. 2004. Disponível em: https://portalseer.ufba.br/ index.php/crh/article/view/18490. Acesso em: 04 mai. 2020.

ANTUNES, R. Os Sentidos do trabalho: Ensaio sobre a afirmação e a negação do trabalho. 2. ed. rev. e ampl. São Paulo: Boitempo, 2009.

ANTUNES, R. Adeus ao Trabalho? ensaio sobre as metamorfoses e a centralidade do mundo do trabalho. 16. ed. São Paulo: Cortez, 2015.

BARROSO, L. R. Interpretação e aplicação da constituição. 7. ed. São Paulo: Saraiva, 2009.

BATAGLIA, F. Filosofia do trabalho. Tradução: Luiz Washington Vita e Antônio D’Elia. São Paulo: Saraiva, 1958.

BAUMAN, Z. Modernidade líquida. Tradução: Plínio Dentzien. Rio de Janeiro: Zahar, 2001.

BRASIL. Decreto-Lei $n^{\circ} 5.452$, de $1^{\circ}$ de maio de 1943. Aprova a Consolidação das Leis do Trabalho. Brasília, DF: Presidência da República. Casa Civil, Subchefia para Assuntos Jurídicos, 1943. Disponível em: http://www.planalto.gov.br/ccivil_03/decreto-lei/Del5452.htm. Acesso em: 04 mai. 2020.

BRASIL. [Constituição (1988)]. Constituição da República Federativa do Brasil de 1988. Senado Federal: Centro Gráfico, 1988. Disponível em: http://www.planalto.gov.br/ccivil_03/constituicao/constituicao.htm. Acesso em: 04 mai. 2020.

BRASIL. Lei $\mathrm{n}^{\circ}$ 8.212, de 24 de julho de 1991. Dispõe sobre a organização da Seguridade Social, institui Plano de Custeio, e dá outras providências. Brasília, DF: Presidência da República, Casa Civil, Subchefia para Assuntos Jurídicos, 1991. Disponível em: http://www.planalto.gov.br/ccivil_03/leis/L8212cons.htm. Acesso em: 04 mai. 2020. 
BRASIL. Lei $n^{\circ}$ 9.876, de 26 de novembro de 1999. Dispõe sobre a contribuição previdenciária do contribuinte individual, o cálculo do benefício, altera dispositivos das Leis nos 8.212 e 8.213, ambas de 24 de julho de 1991, e dá outras providências. Brasília, DF: Presidência da República, Casa Civil, Subchefia para Assuntos Jurídicos, 1999. Disponível em: http://www.planalto. gov.br/ccivil_03/leis/L9876.htm. Acesso em: 04 mai. 2020.

BRASIL. Lei $\mathbf{n}^{\circ}$ 10.406, 10 de janeiro de 2002. Institui o Código Civil. Brasília, DF: Presidência da República, Casa Civil, Subchefia para Assuntos Jurídicos, 2002. Disponível em:

http://www.planalto.gov.br/ccivil_03/LEIS/2002/L10406.htm. Acesso em: 04 mai. 2020.

BRASIL. Lei complementar $n^{\circ}$ 123, de 14 de dezembro de 2006. Institui o Estatuto Nacional da Microempresa e da Empresa de Pequeno Porte; altera dispositivos das Leis no8.212 e 8.213, ambas de 24 de julho de 1991, da Consolidação das Leis do Trabalho - CLT, aprovada pelo Decreto-Lei no 5.452, de 10 de maio de 1943, da Lei no 10.189, de 14 de fevereiro de 2001, da Lei Complementar no 63, de 11 de janeiro de 1990; e revoga as Leis no 9.317, de 5 de dezembro de 1996, e 9.841, de 5 de outubro de 1999. Brasília, DF:

Presidência da República, Casa Civil, Subchefia para Assuntos Jurídicos, 2006. Disponível em: http://www.planalto.gov.br/ccivil_03/LEIS/LCP/Lcp123.htm. Acesso em: 04 mai. 2020.

BRASIL. Lei $\mathrm{n}^{\circ}$ 13.982, 02 de abril de 2020. Altera a Lei $n^{\circ} 8.742$, de 7 de dezembro de 1993, para dispor sobre parâmetros adicionais de caracterização da situação de vulnerabilidade social para fins de elegibilidade ao benefício de prestação continuada (BPC), e estabelece medidas excepcionais de proteção social a serem adotadas durante o período de enfrentamento da emergência de saúde pública de importância internacional decorrente do coronavírus (Covid19) responsável pelo surto de 2019, a que se refere a Lei no 13.979, de 6 de fevereiro de 2020. Brasília, DF: Presidência da República, Secretaria-Geral. Subchefia para Assuntos Jurídicos, 2020. Disponível em: http://www.planalto.gov.br/ccivil_03/_ato2019-2022/2020/lei/L13982.htm. Acesso em: 04 mai. 2020.

BRASIL. Decreto $n^{0} 10.316,07$ de abril de 2020. Regulamenta a Lei $n^{\circ}$ 13.982, de 2 de abril de 2020, que estabelece medidas excepcionais de proteção social a serem adotadas durante o período de enfrentamento da emergência de saúde pública de importância internacional decorrente do coronavírus (covid-19). Brasília, DF: Presidência da República. SecretariaGeral. Subchefia para Assuntos Jurídicos, 2020. Disponível em: http://www.planalto.gov.br/ccivil_03/_ato2019-2022/2020/decreto/D10316.htm. Acesso em: 04 mai. 2020.

BUSCH, H-C S. Exteriorização e economia: a teoria hegeliana do trabalho e da sociedade civil. In: MERCURE, D.; SPURK, J. (org.). O trabalho na história do pensamento ocidental. Tradução: Patrícia Chittoni Ramos Reuillard e Sônia Guimarães Taborba. Petrópolis: Vozes, 2005, p. 88-112. 
CACCIAMALI, M. C. Um estudo sobre o setor informal urbano e formas de participação na produção. 1982. 163 f. Tese (Doutorado em Economia) Faculdade de Economia e Administração da Universidade de São Paulo, 1982.

COSTA, M. da S. Trabalho informal: um problema estrutural básico no entendimento das desigualdades na sociedade brasileira. Caderno CRH, Salvador, vol. 23, n. 58, p. 171-190, jan./abr. 2010. Disponível em: http://www.scielo.br/scielo.php?pid=S010349792010000100011\&script=sci_abstract\&tIng=pt. Acesso em: 04 mai. 2020.

CUNHA, A. M. A lógica de apropriação dos espaços públicos na cidade de Fortaleza pelo trabalhador de rua. 2007. 236 f. Tese (Doutorado em Serviço Social) - Centro de Ciências Sociais Aplicadas da Universidade Federal de Pernambuco, 2007.

DELGADO, G. N. Estado Democrático de Direito e Direito Fundamental ao Trabalho Digno. In: DELGADO, M. G.; DELGADO, G. N. (Org.). Constituição da República e Direitos Humanos: Dignidade da pessoa humana, justiça social e direito do trabalho. São Paulo: LTr, 2012, p. 55-67.

DELGADO, G. N. Direito fundamental ao trabalho ao trabalho digno. 2. ed. São Paulo: LTr, 2015.

DELGADO, M. G. Curso de direito do trabalho. 15. ed. rev. e ampl. São Paulo: LTr, 2016.

FERREIRA, A. B. de H. Dicionário Aurélio da língua portuguesa. 5. ed. Curitiba: Editora Positivo, 2010.

FERREIRA FILHO, M. G. Estado de Direito e Constituição. 4. ed. rev. e atual. São Paulo: Saraiva, 2007.

GAGLIANO, P. S.; PAMPLONA FILHO, R. Novo Curso de Direito Civil: contratos. Tomo 2: contratos em espécie. Vol. IV. 3. ed. rev. e atual. São Paulo: Saraiva, 2010.

HART, K. Informal Income Opportunities and Urban Employment in Ghana. The Journal of Modern African Studies, Cambridge, v. 1, n.1, p. 61-89, 1973.

INSTITUTO BRASILEIRO DE GEOGRAFIA E ESTATÍSTICA. Pesquisa Nacional por Amostras de Domicilio (PNAD). Rio de Janeiro: IBGE, 2020. Disponível em: https://www.ibge.gov.br/estatisticas-novoportal/sociais/trabalho/ 9173 -pesquisa-nacional-por-amostra-de-domicilios-continua-trimestral.html? $=\& t=$ resultados. Acesso em: 04 mai. 2020.

JORDÃO, A. P. F.; STAMPA, Inez. Trabalho precário em pauta: a experiência dos ambulantes nos trens da RMRJ. Em pauta, Rio de Janeiro, vol. 14, n. 37, p. 88-105, jan./jun. 2016. Disponível em: http://www.e-publicacoes.uerj.br/index. php/revistaempauta/article/view/25397. Acesso em: 04 mai. 2020. 
MALAGUTI, M. L. Crítica à razão informal: a imaterialidade do salariado. São Paulo: Boitempo, 2000.

MARX, K. O capital: livro I - o processo de produção do capital. Tradução de Reginaldo San'Anna. 15. ed. Rio de Janeiro: Bertrand Brasil, 1996.

MEIRELES, E. A constituição do trabalho. In: MONTESSO, C. J.; FREITAS; M. A. de; STERN, M. de F. C. B. Direitos sociais na Constituição de 1988: uma análise crítica vinte anos depois. São Paulo: LTr, 2008, p. 50-74.

NORONHA, E. G. "Informal", ilegal, injusto: percepções do mercado de trabalho no Brasil. Revista Brasileira de Ciências Sociais, São Paulo, vol. 18, n. 53, p. 111/179, out. 2003. Disponível em: http://www.scielo.br/scielo.php?pid=S010269092003000300007\&script=sci_abstract\&tlng=pt. Acesso em: 04 mai. 2020.

NUNES, C. R. P. Análise do desenvolvimento da formalização do microempreendedor individual - MEl e as suas relações negociais no Brasil. Scientia luris, Londrina, vol. 7, n. 2, p. 29-54, dez. 2013. Disponível em: http:// www.uel.br/revistas/uel/index.php/iuris/article/view/16401. Acesso em: 04 mai. 2020.

ORGANIZAÇÃO INTERNACIONAL DO TRABALHO (OIT). A OIT e a economia informal. Escritório da OIT em Lisboa, 2006.

RANGEL, F. Novas experiências, outros significados: repensando o trabalho no comércio popular. Revista Colombiana de Sociologia, Bogotá, v. 40, n. 2, p. 67-85, jul./dez. 2017. Disponível em: https://dialnet.unirioja.es/servlet/articulo? codigo $=6157825$. Acesso em: 04 mai. 2020.

SANTOS, B. de S. Para além do pensamento abissal: das linhas globais a uma ecologia de saberes. Novos Estudos, São Paulo, n. 71-94, nov. 2007.

SÃO PAULO. Decreto ${ }^{\circ} \mathbf{6 4 . 8 8 1}, 22$ de março de 2020. Decreta quarentena no Estado de São Paulo, no contexto da pandemia do COVID-19 (Novo Coronavírus), e dá providências complementares. São Paulo, SP: Secretaria de Governo, 2020. Disponível em: https://www.al.sp.gov.br/norma/?id=193361. Acesso em: 04 mai. 2020.

SARLET, I. W. Dignidade da pessoa humana e direitos fundamentais na Constituição Federal de 1988. 9. ed. rev. e atual. Porto Alegre: Livraria do Advogado Editora, 2011.

SENNETT, R. A corrosão do caráter: consequências pessoais do trabalho no novo capitalismo. Tradução de Marcos Santarrita. 7. ed. Rio de Janeiro:

Record, 2003.

SINGER, P. Economia política do emprego. São Paulo: Hucitec, 1978.

SOTO, H. de. Economia subterrânea: uma análise da realidade peruana.

Tradução: Gilson Schwartz. Rio de Janeiro: Globo, 1987. 
SPURK, J. A noção de trabalho em Marx. In: MERCURE, Daniel; SPURK, Jan (org.). $O$ trabalho na história do pensamento ocidental. Tradução: Patrícia Chittoni Ramos Reuillard e Sônia Guimarães Taborba. Petrópolis: Vozes, 2005, p. 189-211.

VARGAS, J. O mundo, o Brasil e a informalidade do trabalho: uma abordagem conceitual. Capital Científico - Eletrônica (RCCe), Guarapuava, vol. 14, n. 3, jul./set. 2016. Disponível em:

http://revistas.unicentro.br/index.php/capitalcientifico/article/view /4029/3140.

Acesso em: 04 mai. 2020.

VIANA, M. C. de S. A discussão histórica da informalidade: significados e formas de representação. 2006. 200 f. Tese (Doutorado em Ciências Humanas: Sociologia) - Instituto Universitário de Pesquisas do Rio de Janeiro, Rio de Janeiro, 2006.

Recebido em | 12/10/2019

Aprovado em | 01/06/2020

Revisão Português/Inglês | Letícia Gomes Almeida

\section{ISOBRE OS AUTORES | ABOUT THE AUTHORS}

\section{LENÍCIO LEMOS PIMENTEL}

Juiz do Trabalho Substituto do Tribunal Regional do Trabalho da $3^{a}$ Região. Mestre em Gestão Integrada do Território pela Universidade Vale do Rio Doce (UNIVALE). Pós-graduado em Direito do Trabalho e em Direito Processual do Trabalho pela Faculdade Pitágoras. Ex-Técnico Judiciário do Tribunal Regional do Trabalho da $3^{\text {a }}$ Região. E-mail: lenicio.pimentel@hotmail.com.

\section{ALEXANDRE PIMENTA BATISTA PEREIRA}

Juiz do Trabalho Substituto do Tribunal Regional do Trabalho da $3^{a}$ Região. Doutor e Mestre em Direito pela Universidade Federal de Minas Gerais (UFMG). Professor do curso de Direito e de Mestrado em Gestão Integrada do Território na Universidade Vale do Rio Doce (UNIVALE). Bolsista do Serviço Alemão de Intercâmbio Acadêmico (DAAD) e Pesquisador-Visitante na Universidade de Gießen/Alemanha (2006-2008). Pesquisador-Visitante no MaxPlanck-Institut für ausländisches und internationales Privatrecht em Hamburgo/ Alemanha (2010-2011). Ex-Professor da Universidade Federal de Viçosa. Email: alexandre_pereira@hotmail.com. 